\title{
Sesquiterpene Lactones from Inula montana $\mathbf{L}$.
}

\author{
María A. González-Romero, Lucinda Villaescusa-Castillo and \\ Ana M. Díaz-Lanza* \\ Departamento de Farmacología, Facultad de Farmacia, Universidad de Alcalá, \\ 28871 Alcalá de Henares, Madrid, Spain. Fax: 918854679. E-mail: tfamdl@farma.alcala.es \\ * Author for correspondence and reprint requests \\ Z. Naturforsch. 55c, 697-700 (2000); received April 10/May 29, 2000 \\ Asteraceae, Inula montana L., Sesquiterpene Lactones \\ Aerial parts of Inula montana were investigated for its sesquiterpenoid composition. Five \\ sesquiterpene lactones, isoinuviscolide, gaillardin, $1 \beta$-hydroxy-3 $\beta$-acetoxy-eudesm-4(15),

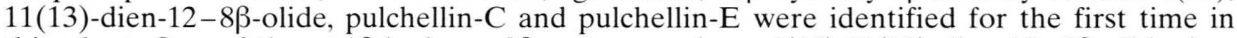

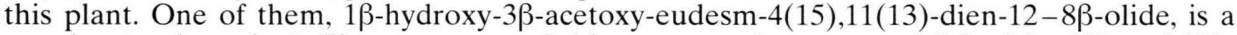 \\ novel natural product. The structures of this compounds were established by $1 \mathrm{D}$ and $2 \mathrm{D}$ - \\ NMR spectroscopy.
}

\section{Introduction}

Inula montana L. (tribe Inuleae, fam. Asteraceae) is a perennial species occurring in the east of Spain on alkaline and dry soils, extending to west of France and east of Italy (Tutin, 1976). Several species from the genus Inula are traditionally used in folk medicine as antipyretic (Muzaffer et al., 1992), antiinflammatory and hepatoprotective drugs (Kurma and Mishra, 1997). However, there are no data in the literature on the chemical constituents and the possible pharmacological effects of Inula montana.

The secondary plant metabolites that mediate these pharmacological effects are mainly sesquiterpene lactones. This class of compounds includes over 3000 naturally occurring substances, one of the largest group of plant products described (Fischer, 1991).

Sesquiterpene lactones occur in many plant families, but are most widely distributed within the Asteraceae. They include a wide variety of biological and pharmacological activities. Antitumor, antimicrobial, antifeedant, cytotoxic, antibacterial, antifungal, allergenic contact dermatitic and plant growth regulatory activity of several sesquiterpene lactones has been previously reported (Beckman et al., 1998; Picman and Towers, 1983; Picman,1984; Warshaw and Zug, 1996). In a previous paper we have described the antileishmanial activity of a chloroform extract from the aerial parts of Inula montana against Leishmania infantum (promastigote forms) (Martín et al., 1998).
In the present paper, we report the isolation and identification of five sesquiterpene lactones, isoinuviscolide, gaillardin, pulchellin- $\mathrm{E}$, pulchellin- $\mathrm{C}$ and the new natural product $1 \beta$-hydroxy- $3 \beta$-acetoxy-eudesm-4(15),11(13)-dien-12-8 $\beta$-olide, for the first time from Inula montana.

\section{Results and Discussion}

In the chloroform extract of the leaves of Inula montana L. the following known sesquiterpene lactones were identified: isoinuviscolide (1), gaillardin (2), pulchellin E (4) and pulchellin-C (5). In addition, we have isolated and identified one new natural product, $1 \beta$-hydroxy-3 $\beta$-acetoxy-eudesm4(15),11(13)-dien-12-8 $\beta$-olide (3). The structures of the known compounds (Fig. 1) were determined by comparison of their spectroscopic features with those reported in the literature (Yoshioka et al., 1970; Sanz et al., 1991; Ito and Lida, 1981; Pired, 1977).

Compound $\mathbf{3}$ was obtained as a yellow syrup and had the molecular formula $\mathrm{C}_{17} \mathrm{H}_{22} \mathrm{O}_{5}(\mathrm{~m} / z$ 306) as established by EIMS. The IR spectrum confirmed the presence of the $\mathrm{OH}$ group $\left(3600 \mathrm{~cm}^{-1}\right)$ and the acetyl carbonyl $\left(1760 \mathrm{~cm}^{-1}\right)$. The ${ }^{1} \mathrm{H}-\mathrm{NMR}$ spectrum (Table I) showed four multiplets between 6.5 and 4.5 ppm corresponding to two exocyclic methylene groups. Two broadened singlets at 84.97 and 4.66 were assigned to the methylene protons at C-4 and the presence of a pair of doublets at $\delta 6.15$ and $5.61(1 \mathrm{H}$ each $)$ is character- 


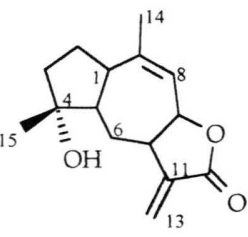

1

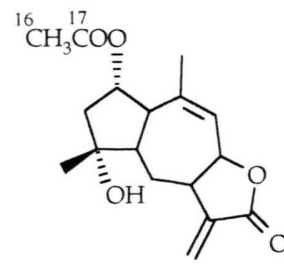

2

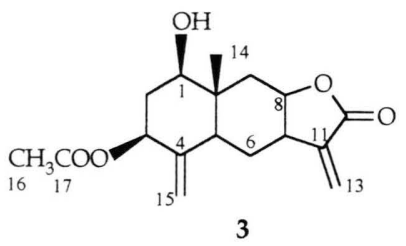<smiles>C=C1C(=O)OC2C[C@@]3(C)C[C@H](O)[C@@H](OC(C)=O)C(=C)C3CC12</smiles><smiles>C=C1C(=O)OC2C[C@@]3(C)C[C@H](O)[C@@H](O)C(=C)C3CC12</smiles>

5

Fig. 1. Structures for sesquiterpene lactones 1-5.

Table I. ${ }^{1} \mathrm{H}$ NMR chemical shift assignments for the isolated sesquiterpene lactones.

\begin{tabular}{|c|c|c|c|c|c|}
\hline $\mathrm{H}$ & 1 & 2 & 3 & 4 & 5 \\
\hline 1 & 2.57 & 2.60 & $3.49(J=11.8 / 4.3)$ & 1.32 and 1.94 & 1.6 and 1.82 \\
\hline 2 & 1.72 and 1.93 & 5.20 & $\begin{array}{l}1.62 \text { and } 2.16 \\
(J=11.8)\end{array}$ & 3.71 & 3.43 \\
\hline 3 & 1.58 and 1.78 & 1.97 and 1.97 & $5.17(J=1.5)$ & 4.99 & 3.74 \\
\hline 4 & - & - & - & - & - \\
\hline 5 & 1.48 & 2.20 & $1.75(J=1.5)$ & 1.93 & 1.97 \\
\hline 6 & 1.45 and 2.50 & 1.49 and 2.54 & $\begin{array}{l}1.50 \text { and } 1.78 \\
(J=11.6 / 6.2)\end{array}$ & 1.35 and 1.76 & 1.05 and 1.82 \\
\hline 7 & 2.51 & 2.59 & $2.96(J=6.2 / 1.5)$ & 2.96 & 3.10 \\
\hline 8 & 4.81 & 4.57 & $4.54(J=4.9 / 2.0)$ & 4.48 & 4.54 \\
\hline 9 & 5.80 & 5.89 & $\begin{array}{l}1.45 \text { and } 2.63 \\
(J=15.7)\end{array}$ & 1.50 and 2.26 & 1.60 and 2.20 \\
\hline 10 & - & - & - & - & - \\
\hline 11 & - & - & - & - & - \\
\hline 12 & - & - & - & - & - \\
\hline 13 & 5.90 and 6.10 & 6.14 and 5.64 & 6.15 and 5.61 & 5.59 & 6.07 and 5.71 \\
\hline 14 & 1.82 & 1.84 & 0.82 & 0.82 & 0.80 \\
\hline 15 & 1.19 & 1.22 & 4.97 and 4.66 & 4.90 and 4.63 & 5.26 and 4.70 \\
\hline 16 & - & 2.05 & 2.13 & 2.15 & - \\
\hline 17 & - & - & - & - & - \\
\hline
\end{tabular}

istic of a methylenic group (C-11) conjugated with a lactonic carbonyl group. The region 2.2-0-8 ppm showed two methyl singlets at 2.13 and $0.82 \mathrm{ppm}$. The chemical shift of the methyl singlet at $\delta 2.13$ indicated that this methyl group should be adjacent to an oxygen function (acetate methyl).

The ${ }^{13} \mathrm{C}$-NMR spectrum (Table II) showed two signals ( $\delta 170.2$ and 169.9) of carbonyl groups of the quaternary carbons, one at $\delta 170.2$ was clearly due to the lactone carbonyl, while the other at $\delta 169.9$ could be assigned to an acetyl group. The multiplicity of each carbon was achieved by the
DEPT experiment, which revealed the presence of two methyl, five methylene, five methine and five quaternary carbons. The assignment of proton and carbon signals was achieved from DQCOSY and 2D-TOCSY Homonuclear Hartmann-Hahn Spectroscopy (HOHAHA) (mixing time $=80 \mathrm{~ms}$ ) experiments and also from ${ }^{1} \mathrm{H}-{ }^{13} \mathrm{C}$ heteronuclear multiple quantum (HMQC) and multiple bond correlations (HMBC).

The compounds 1, 2, 4 and $\mathbf{5}$ were obtained as white crystalline solids. The ${ }^{1} \mathrm{H}$ NMR spectra of $\mathbf{1}$ and $\mathbf{2}$ suggested two guaianolides with an $\alpha$-meth- 
Table II. ${ }^{13} \mathrm{C}$ NMR chemical shift assignments for the isolated sesquiterpene lactones.

\begin{tabular}{llllll}
\hline & $\mathbf{1}$ & $\mathbf{2}$ & $\mathbf{3}$ & $\mathbf{4}$ & $\mathbf{5}$ \\
\hline 1 & 47.2 & 51.9 & 76.9 & 47.9 & 49.3 \\
2 & 25.9 & 77.5 & 36.9 & 69.6 & 73.1 \\
3 & 42.0 & 48.5 & 71.0 & 80.0 & 79.5 \\
4 & 80.4 & 79.5 & 141.7 & 141.5 & 150.4 \\
5 & 53.5 & 51.5 & 41.7 & 44.3 & 45.2 \\
6 & 32.0 & 30.4 & 26.3 & 27.1 & 28.7 \\
7 & 47.9 & 47.2 & 40.2 & 40.8 & 41.3 \\
8 & 83.7 & 84.4 & 76.0 & 76.2 & 78.7 \\
9 & 126.7 & 128.7 & 37.8 & 40.5 & 41.6 \\
10 & 143.1 & 138.0 & 29.7 & 33.5 & 34.6 \\
11 & 141.6 & 141.4 & 144.6 & 143.5 & 144.0 \\
12 & 172.3 & 172.1 & 169.9 & 170.5 & 172.6 \\
13 & 119.5 & 119.9 & 120.6 & 120.7 & 121.0 \\
14 & 21.4 & 22.8 & 11.2 & 18.5 & 19.1 \\
15 & 23.8 & 26.7 & 105.6 & 106.4 & 106.3 \\
16 & - & 21.5 & 21.0 & 20.9 & - \\
17 & - & 172.6 & 170.2 & 170.2 & - \\
\hline
\end{tabular}

ylene- $\gamma$-lactone group. The difference between compounds $\mathbf{1}$ and $\mathbf{2}$ was the presence of the acetyl group at $\mathrm{C}-2$ in $\mathbf{2}$. As expected the $\mathrm{H}-2$ signal was shifted downfield ( $\delta 5.20)$ and an acetate methyl singlet was visible $(\delta 2.05)$.

The ${ }^{1} \mathrm{H}$ NMR spectra of $\mathbf{4}$ and $\mathbf{5}$ suggested two eudesmanolides: $2 \alpha$-hydroxy- $3 \beta$-acetoxy-isoalantolactone and $2 \alpha, 3 \beta$-dihydroxy-isoalantolactone, respectively. Their structures were determined by comparison of their spectroscopic features with those reported in the literature (Yoshioka et al., 1970).

\section{Experimental}

MS spectra were obtained in a Hewlett Packard 5988 A mass spectrometer. Analytical TLC was performed on precoated $\mathrm{Si}$ gel plates (Kieselgel G-60, F-254, $0.25 \mathrm{~mm}$, Merck) using mixtures of chloroform-methanol. Visualization of the TLC plates was achieved with a long wavelength UV lamp and sulfuric acid spray reagent.

All 1D and 2D NMR spectra were recorded by a Varian Unity Plus spectrometer in $\mathrm{CDCl}_{3}$ or $\mathrm{CD}_{3} \mathrm{OD}$ solutions $\left({ }^{1} \mathrm{H}\right.$ at $500 \mathrm{MHz},{ }^{13} \mathrm{C}$ at 125 $\mathrm{MHz}$ ). Multiplicities were assigned through DEPT experiments. The standard pulse sequences from the Varian software were used for homonuclear and heteronuclear correlation experiments (DQCOSY, TOCSY, HMQC and HMBC).

\section{Collection, extraction and isolation}

The aerial parts of Inula montana were collected in San Andrés del Congosto (Guadalajara, Spain) in July 1996 and identified by Professor Carmen Bartolomé Esteban. A voucher specimen is kept in the Department of Vegetal Biology, Faculty of Sciences, University of Alcalá (Madrid, Spain).

Air-dried plant material $(820 \mathrm{~g})$ was extracted with chloroform. The dry chloroform extract $(23.43 \mathrm{~g})$ was subjected to solvent partitioning between n-hexane and $\mathrm{H}_{2} \mathrm{O} / \mathrm{MeOH}(5 / 95 \mathrm{v} / \mathrm{v})$. The $\mathrm{H}_{2} \mathrm{O} / \mathrm{MeOH}$ portion (12.84 g) was column chromatographed over silicagel, eluted with chloroform and mixtures chloroform-methanol of increasing polarity, giving fractions $A_{1}-A_{20}$. Fractions $A_{1}$ to $A_{10}$ were eluted with pure chloroform. Fraction $\mathrm{A}_{2}$ was submitted to sucesive flash column chromatography (CC) over silicagel (chloroform-methanol and toluene-diethyl ether) to give isoinuviscolide $(\mathbf{1}, 14.4 \mathrm{mg})$. Fraction $\mathrm{A}_{5}$ was rechromatographed over silicagel (hexane-acetone) to give gaillardin $(\mathbf{2}, 302.7 \mathrm{mg})$. Fraction $\mathrm{A}_{8}$ was submitted to CC over silicagel (toluene-diethyl ether) to give the sesquiterpene lactones $1 \beta$-hydroxy-3ß-acetoxy-eudesm-4(15),11(13)-dien-12$8 \beta$-olide $(\mathbf{3}, 13.6 \mathrm{mg})$ and pulchellin-E $(\mathbf{4}, 29.5 \mathrm{mg})$. Finally, fraction $\mathrm{A}_{9}$ was rechromatographed over silicagel (toluene-diethyl ether) to give pulchellinC $(\mathbf{5}, 10.7 \mathrm{mg})$.

\section{Acknowledgements}

This work was realized with the financial support of the following institutions: PICASSO (Acciones Integradas Hispano-Francesas, Refs. H-211 and 98-B), FIS (Ministerio de Sanidad y Consumo, Ref. 94/1671). CAM (Comunidad Autónoma de Madrid, Ref. C101/91), Universidad de Alcalá (E001/99), and Consejería de Educación y Cultura de la Comunidad Autónoma de Madrid (Convocatoria 1998). 
Beekman A. C., Wierenga P. K., Woerdenbag H. J., Van Uden W., Pras N., Konings A. W. T., El-Feraly F., Calal A. M. and Wikstrom H. V. (1998), Artemisinin-derived sesquiterpene lactones as potential antitumor compounds: cytotoxic action against bone marow and tumour cell. Planta Med. 64, 615-619.

Fischer N. H. (1991), Sesquiterpene lactones. In: Meth. Plant. Biochem. (Dey P. M. and Harborne J. B., ed.). Academic Press, New York 7, 187-211.

Ito K. and Lida T. (1981), Seven sesquiterpene lactones from Inula britannica var. chinensis. Phytochemistry 20, $271-273$.

Kurma Rao S. and Mishra S. H. (1997), Screening of anti-inflammatory and hepatoprotective activities of alantolactone, isolated from the roots of Inula racemosa. Indian Drugs 34 (10), 571-575.

Martín T., Villaescusa L., Gasquet M., Delmas F., Bartolomé C., Díaz-Lanza A. M., Ollivier E. and Balansard G. (1998), Screening for protozoocidal activity of Spanish plants. Pharm. Biol. 36, 56-62.

Muzaffer A., Susan T., Joy S. and Kundu A. B. (1992), Antiinflammatory and antipyretic activity of vicolides of Vicoa indica. Indian J. Exp. Biol. 30, 38-41.
Picman A. K. (1984), Antifungal activity of sesquiterpene lactones. Biochem. System. Ecol. 12, 13-18.

Picman A. K. and Towers G. H. N. (1983), Antibacterial activity of sesquiterpene lactones. Biochem. System. Ecol. 11, 321-327.

Sanz J. F., Ferrando C. and Marco J. A. (1991), Oxigenated nerolidol esters and eudesmane acids from Inula viscosa. Phytochemistry 30, 3653-3655.

St. Pired J. (1977), Terpenes of Compositae plants. IV. Isolation of gaillardin from flowers of Inula britannica L. L. Rocz. Chem. 51, 1277-1279.

Tutin T. G. (1976), Flora Europaea (Tutin T. G., ed.). Vol. 4, 135. Cambridge University Press, Cambridge.

Warshaw E. M. and Zug A. K. (1996), Sesquiterpene lactone allergy. Am. J. Contact Derm. 7, 1-23.

Yoshioka H., Mabry T. J., Dennis N. and Herz W. (1970), Structure and stereochemistry of pulchellin B, C, E and F. J. Org. Chem. 35 3, 627-630. 